\title{
A captura das crianças e dos adolescentes: refletindo sobre controvérsias públicas envolvendo gênero e sexualidade nas políticas de educação
}

\section{The capture of children and adolescents: reflecting on public controversies involving gender and sexuality in education policies}

\author{
La captura de niños y adolescentes: reflexiones \\ sobre las controversias públicas que involucran el \\ género y la sexualidad en las políticas educativas
}

Vanessa Jorge Leite ${ }^{1}$

DOI: http://dx.doi.org/ 10.20435/serie-estudos.v20i52.1354

\begin{abstract}
Resumo: A escola tem sido lócus permanente do confronto de concepções e valores em relação à sexualidade e ao gênero. Esses enfrentamentos se mostram: (1) na elaboração de normativas da política de educação; (2) em controvérsias públicas que envolvem a política de educação e gênero e sexualidade; (3) bem como no fazer cotidiano das escolas e dos educadores, nos embates em torno dos currículos escolares. Nos últimos anos, assistimos a diversas controvérsias, em que as expressões de gênero e sexualidade infantojuvenis e a escola estiveram no centro. Esse artigo volta seu olhar para o pânico moral criado em torno do Projeto Escola sem Homofobia (ESH), chamado de "kit gay" por seus detratores, a partir de 2011. A trajetória do ESH nos possibilita refletir sobre o papel estratégico dessa polêmica para os "destinos" da política de educação nos últimos anos no país. O episódio do ESH pode ser considerado um "estopim" para que outros projetos e temas muito vinculados a uma pauta "conservadora" ganhassem força na sociedade brasileira. Acompanhamos o acionamento da terminologia "ideologia de gênero" em torno dos planos de educação no país, e mais recentemente, no processo eleitoral para a Presidência da República, vimos o "kit gay" ser um dos principais artefatos da campanha do presidente eleito. Essas controvérsias têm como pontos de interseção o confronto de moralidades em relação ao gênero e à sexualidade e a mobilização do discurso de defesa das crianças e dos adolescentes.
\end{abstract}

Palavras-chave: escola sem homofobia; gênero e sexualidade; infância e adolescência.

Abstract: Schools have been permanent loci of confrontations between different sexuality- and gender-related conceptions and values. Such confrontations show (1) in the elaboration of

1 Universidade do Estado do Rio de Janeiro (UERJ), Rio de Janeiro, Rio de Janeiro, Brasil. 
education policy norms; (2) in public controversies involving gender and sexuality and education policies; (3) in daily school life and in educators' daily work, as well as in conflicts over the school curricula. In recent years, a number of controversies have developed over both the school environment, and sexuality and gender expressions of children and youth. This article addresses the moral panic developed around the School Without Homophobia Project (ESH), dubbed "gay kit" by its detractors, from 2011 on - so as to enable us to reflect on the strategic role of such controversy to the developments in education policy in Brazil in recent years. The ESH episode has probably contributed to the strengthening of other projects and themes closely linked to a "conservative" agenda in Brazil. We have tracked how the phrase "gender ideology" was used in debates over education plans around the country. More recently, in the 2018 presidential elections, the "gay kit" was one of the president-elect campaign's main themes. What all such controversies have in common are the confrontation between different sexuality- and gender-related moralities and the alleged need to protect children and adolescents.

Keywords: school without homophobia; gender and sexuality; childhood and adolescence.

Resumen: La escuela ha sido un lugar permanente de confrontación de concepciones y valores en relación con la sexualidad y el género. Estas confrontaciones se muestran: (1) en la elaboración de normas de política educativa; (2) en controversias públicas que involucran políticas de educación y políticas de género y sexualidad; (3) así como en el trabajo diario de las escuelas y los educadores, en los enfrentamientos en torno al currículo escolar. En los últimos años, hemos visto una serie de controversias, donde las expresiones de género y sexualidad en los niños y adolescentes y la escuela han estado en el centro. Este artículo dirige su mirada al pánico moral creado en torno al Proyecto Escuela Sin Homofobia (ESH), Ilamado "kit gay" por sus detractores, desde 2011. La trayectoria de ESH nos permite reflexionar sobre el papel estratégico de esta controversia para los "destinos" de la política educativa en los últimos años en Brasil. El episodio de ESH puede considerarse un "disparador" para que otros proyectos y temas estrechamente vinculados a una agenda "conservadora" ganaran fuerza en la sociedad brasileña. Seguimos la activación de la terminología "ideología de género" en torno a los planes de educación en el país. Más recientemente, en el proceso electoral para la presidencia de la república, vimos que el "kit gay" era uno de los principales artefactos de la campaña del presidente electo. Estas controversias tienen como puntos de intersección la confrontación de moralidades en relación con el género y la sexualidad y la movilización del discurso de defensa de los niños y adolescentes.

Palabras clave: escuela sin homofobia; género y sexualidade; infância y adolescência.

\section{INTRODUÇÃO}

A escola tem sido lócus permanente do confronto de concepções e valores em relação à sexualidade e ao gênero. As expressões de gênero e sexualidade infantojuvenis têm ocupado um papel fundamental no conflito entre ideários na sociedade brasileira. Como propõe Carrara (2015), podemos dizer que vivemos hoje em um contexto social e político em que diferentes moralidades em relação à sexualidade e ao gênero se confrontam na sociedade e disputam lugares de 
A captura das crianças e dos adolescentes: refletindo sobre controvérsias públicas envolvendo gênero e sexualidade nas políticas de educação

poder nas estruturas do Estado. Uma dessas moralidades foi forjada no século XIX e em boa parte do século XX; em seus termos, a fronteira entre o bom e mau sexo era estabelecida, sobretudo, por seu caráter reprodutivo ou não e, por consequência, a heterossexualidade era a norma. Acompanhamos a emergência de uma outra moralidade baseada na ideia do exercício da sexualidade e do gênero enquanto direitos, na existência do que temos chamado de "direitos sexuais e à livre expressão de gênero" ${ }^{2}$.

O ideário dos direitos sexuais dissemina uma perspectiva da sexualidade como algo positivo em si mesma, um direito humano, não necessariamente ligada à violência, ao casamento ou à reprodução. Contudo uma das complexidades do processo que vivemos é de que as concepções sobre as quais os regimes da sexualidade se apoiam não são exatamente sucessivas no tempo, mas convivem tensamente no cenário contemporâneo, em diferentes modos de articulação e, como apontado, de enfrentamento.

E esses enfrentamentos se mostram: (i) na elaboração de normativas da política de educação; (ii) em controvérsias públicas que envolvem a política de educação e gênero e sexualidade; (iii) bem como no fazer cotidiano das escolas e dos educadores, nos embates em torno dos currículos escolares. É fundamental estarmos atentos para essas diferentes dimensões da política de educação, em que se apresentam disputas de concepções, valores e projetos de sociedade. Nos últimos anos, assistimos a diversas controvérsias públicas, nas quais as expressões de gênero e sexualidade infantojuvenis e a escola estiveram no centro.

Este artigo volta seu olhar para a controvérsia em torno do Projeto Escola sem Homofobia (ESH), chamado de "kit gay" por seus detratores, a partir de 2011, remontando atores, arenas e disputas que ele envolveu (LEITE, 2014). Olhar para a trajetória do Projeto Escola sem Homofobia nos possibilita refletir sobre o papel estratégico dessa polêmica para os "destinos" da política de educação nos últimos anos no país. A forma como se posicionaram os múltiplos atores envolvidos no processo e as decorrentes correlações de força fizeram do episódio do ESH

2 Forjada no campo dos direitos humanos, a categoria direitos sexuais foi incorporada ao plano político e acadêmico. Em geral, os autores que discutem aspectos ligados à diversidade sexual e de gênero ainda utilizam essa terminologia, que, a meu ver, começa a ficar restrita para se referir às discussões ligadas tanto a diferentes expressões da sexualidade como também a trânsitos e identidades de gênero. Nesse sentido, optei por incorporar a expressão direitos sexuais e direitos à livre expressão de gênero. 
um "estopim" para que outros projetos e temas muito vinculados a uma pauta conservadora ganhassem força na sociedade brasileira.

$\mathrm{Na}$ esteira das ações governamentais trazidas pelo Programa Brasil sem Homofobia (BRASIL, 2004), a despeito das resistências e limites, a perspectiva de atuar na afirmação das diversidades, inclusive as relacionadas ao gênero e à sexualidade, ganhou alguma ênfase nas políticas de educação de uma forma mais ampla, na década passada. Ainda em 2004, foi criada no Ministério da Educação (MEC) a Secretaria de Educação Continuada, Alfabetização e Diversidade (SECAD³). A Secretaria desencadeou um conjunto de processos voltados à formação de professores nos temas de gênero, sexualidade e diversidade sexual. A partir de parceria do MEC com o movimento LGBTI e organizações da sociedade civil, foi elaborado o ESH. Em 2011, o projeto provocou forte polêmica em todo o país, amplamente divulgada pela mídia. Articulou-se um pânico moral ${ }^{4}$ em torno do projeto, a partir da ideia de que o Estado estaria financiando o "desvirtuamento das crianças".

O projeto, denominado "kit gay" por seus opositores, esteve no centro de um grande conflito, que pode nos ajudar a construir o panorama mais amplo das diferentes posições em jogo. O material produzido pelo projeto, especialmente seus vídeos, que se tornaram públicos, e toda a discussão que o envolveu colocaram em cena personagens que podiam ser lidos como adolescentes gays, lésbicas, bissexuais, travestis, transexuais. Podemos pensar que não foi o conteúdo do material - ou o conteúdo divulgado como se fosse o material - que motivou a polêmica. Há o conteúdo real e o que foi construído no embate.

O Projeto Escola sem Homofobia foi planejado e executado em parceria entre a rede internacional Global Alliance for LGBT Education (GALE) e as organizações não governamentais Pathfinder do Brasil, Comunicação em Sexualidade (ECOS), Soluções Inovadoras em Saúde Sexual e Reprodutiva (Reprolatina) e Associação

3 Em 2011, A SECAD passa a ser denominada Secretaria de Educação Continuada, Alfabetização e Inclusão (SECADI). E, em janeiro de 2019, foi extinta pelo Ministro da Educação.

4 Como propõe Rubin (1998), "o tipo mais importante e consequente de conflito sexual é o que Jeffrey Weeks chamou de 'pânico moral'” (WEEKS, 1981). Segundo a autora, "pânicos morais são o 'momento político' do sexo, em que atitudes difusas são canalizadas em ação política e, a partir disso, em mudança social [...] Devido à sexualidade nas sociedades ocidentais ser tão mistificada, as guerras sobre ela são comumente combatidas a partir de ângulos oblíquos, focadas num alvo falso, conduzidas com paixões deslocadas, e são altamente e intensamente simbólicas". 
A captura das crianças e dos adolescentes: refletindo sobre controvérsias públicas envolvendo gênero e sexualidade nas políticas de educação

Brasileira de Lésbicas, Gays, Bissexuais, Travestis e Transexuais (ABGLT). O projeto foi fruto de uma emenda parlamentar proposta pela deputada Fátima Bezerra (PT-RN), em 2007, a partir de articulações políticas da ABGLT no Congresso Nacional. Em sua fase final de aprovação pelo MEC, foi suspenso publicamente pela presidente Dilma Rousseff em maio de 2011, após forte pressão de setores "conservadores" ${ }^{5}$ do Congresso Nacional.

A primeira apresentação oficial dos resultados do projeto e dos materiais produzidos se deu no dia 23 de novembro de 2010, em um seminário no Congresso Nacional, intitulado "Escola sem Homofobia", em que o projeto nas suas diferentes dimensões foi apresentado. As instituições promotoras apresentaram os dois produtos do projeto: (i) um conjunto de recomendações para políticas públicas, que derivavam de uma pesquisa desenvolvida pelo Projeto $\mathrm{ESH}^{6}$ - cujos dados coletados revelavam a escola como ambiente hostil aos alunos LGBT - e de encontros regionais que foram realizados em vários estados do país logo no início do projeto; (ii) uma estratégia de comunicação que se materializaria no material educativo do projeto?

Em sua apresentação dos materiais e das propostas para sua utilização, a representante da ECOS cunhou a expressão "kit", que foi depois apropriada pelos

5 O termo conservador(es) tem sido mobilizado com frequência no debate público, e uma pergunta a se fazer é sua real capacidade descritiva e analítica. Outra modalidade corrente de seu uso é como categoria de acusação. Nesse sentido, optei por utilizar a palavra conservador(es) entre aspas no texto, quando me refiro a atores específicos, para ressaltar o caráter conjuntural e relacional dessa denominação e chamar atenção para possíveis naturalizações e reificações no uso do termo. (ALMEIDA, 2017; ALMEIDA e TONIOL, 2018).

6 A pesquisa foi desenvolvida pela ONG Reprolatina e intitula-se "Estudo qualitativo sobre a homofobia na comunidade escolar em 11 capitais brasileiras". O objetivo da pesquisa era conhecer a percepção da equipe docente, autoridades e estudantes do 6ㅇ ao 9o ano da rede pública de ensino sobre a situação da homofobia no ambiente escolar.

7 O material educativo, desenvolvido pela ECOS, era composto por um caderno - "Escola sem Homofobia"; um conjunto de seis Boletins Escola sem Homofobia (BOLESHS), destinados aos estudantes, cada um abordando um assunto relacionado ao tema da sexualidade, diversidade sexual e homofobia; e cinco audiovisuais: o vídeo "Torpedo", que apresentava duas adolescentes que estudavam na mesma escola e se envolviam afetivamente; o vídeo "Encontrando Bianca", que se tornou um dos mais polêmicos e apresentava uma jovem travesti na escola; o vídeo "Probabilidade", que apresentava um adolescente bissexual; e outros dois, "Medo de quê?" e "Boneca na mochila", que já eram vídeos antigos produzidos pela ECOS em parceria com outras instituições e não causaram muito impacto público. 
opositores do projeto. Os vídeos do projeto, que se tornariam o foco da polêmica, faziam parte de um conjunto bem mais amplo de materiais educativos. O "kit de material educativo" nem chegou a se tornar público, visto que, ainda em processo de avaliação pelo MEC, o projeto foi suspenso e, segundo o contrato estabelecido na parceria, ele só poderia ser publicado e utilizado após aprovação do ministério, que inclusive, teria a responsabilidade de preparar 6.000 cópias de todo o material. Os vídeos, segundo os proponentes do projeto, "vazaram na internet". Não é possível recuperar aqui toda a trajetória da polêmica, mas destaco alguns flashes dessa controvérsia.

\section{O DESENVOLVIMENTO DA POLÊMICA - A CONSTRUÇÃO DO “CASO”}

Durante o seminário, o então deputado federal Jair Bolsonaro (PP-RJ), que se transformaria no primeiro "inimigo público" do projeto, soube da sua realização. A partir desse momento, o deputado começou a se referir ao projeto, fazendo discurso sobre ele em sessão da Câmara do dia 30 de novembro de 2010, mas ainda sem muito impacto de mídia, com matérias esparsas até o final de 2010. Em seu primeiro discurso sobre o Projeto ESH, Bolsonaro afirmou que na semana anterior teria havido uma reunião da Comissão de Direitos Humanos e Minorias, na qual

[...] estava presente uma plateia composta $100 \%$ de gays, lésbicas, bissexuais, travestis, transexuais e transgêneros. Essa turma toda reunida tomou decisões de que esta Casa não está sabendo [...] Atenção, pais de alunos de 7, 8, 9 e 10 anos da rede pública: no ano que vem, seus filhos vão receber na escola um kit intitulado Combate à Homofobia. Na verdade, é um estímulo ao homossexualismo, à promiscuidade. Esse kit contém DVDs com duas historinhas. Seus filhos de 7 anos vão vê-las no ano que vem, caso não tomemos uma providência agora ${ }^{8}$.

O deputado continuou seu pronunciamento trazendo uma perspectiva bastante utilizada durante toda a polêmica do ESH, de que o discurso de enfrentamento à homofobia mascarava um "aliciamento", desvirtuamento das crianças. Segundo ele,

8 O discurso do deputado na sessão da Câmara de 30/11/2010 foi acessado através do site do Congresso Nacional. Disponível em: http://www.camara.leg.br/internet/SitaqWeb/TextoHTML. asp?etapa=5\&nuSessao=208.4.53.0\&nuQuarto=29\&nuOrador=2\&nulnsercao=0\&dtHorarioQu arto=14:56\&sgFaseSessao=PE\&Data=30/11/2010\&txApelido=JAIR\%20BOLSONARO,\%20PP-RJ 
A captura das crianças e dos adolescentes: refletindo sobre controvérsias públicas envolvendo gênero e sexualidade nas políticas de educação

[...] esses gays e lésbicas querem que nós entubemos, como exemplo de comportamento, a sua promiscuidade [...] Essa história de homofobia é uma história de cobertura para aliciar a garotada, especialmente os garotos que eles acham que têm tendências homossexuais. Está na pesquisa, publicada aqui, o número de garotos gays ou de meninas lésbicas, repito, de 7, 8, 9 e 10 anos [...] Não me agrada falar em homossexual. Eu realmente assumo o que disse na TV Câmara: se um garoto tem desvio de conduta logo jovem, ele deve ser redirecionado para o caminho certo, nem que seja com umas palmadas. Acusam-me de ser violento, mas não sou promíscuo, não sou canalha com as familias brasileiras!

Nesse primeiro discurso, ele já lançava as principais bases argumentativas dos opositores do ESH, que se multiplicaram no início do ano de 2011. Com a polêmica tomando corpo, outros atores "credenciados" começaram a ser acionados. Em várias matérias na imprensa, professores universitários e pesquisadores eram chamados a se posicionar. Como o impasse com o MEC, em relação à aprovação e publicação do material, não se definia, houve uma articulação das instituições proponentes, que solicitaram a algumas instituições pareceres técnicos sobre o projeto. Em fevereiro de 2011, o Conselho Federal de Psicologia (CFP), a Organização das Nações Unidas para a Educação, a Ciência e a Cultura (UNESCO) e o Programa Conjunto da ONU para o HIV/AIDS (UNAIDS) divulgaram pareceres favoráveis ao projeto, o que levou a polêmica de novo à imprensa.

Nesse momento, final de fevereiro de 2011, outro ator surgiu no cenário, o senador Magno Malta (PR-ES). O senador evangélico, que integrava a autodenominada "Frente da Família", foi acusado de, em seus discursos sobre o projeto, tratá-lo como estímulo à pedofilia ${ }^{9}$. Progressivamente, novos parlamentares surgiram no cenário da polêmica do ESH. Jair Bolsonaro manteve seu "ativismo" pela derrubada do Projeto ESH e para dar visibilidade a seus argumentos. Chegamos, nesse momento, ao ápice da mobilização pública em relação ao projeto, o mês de maio de 2011.

No início do referido mês, Jair Bolsonaro lançou um panfleto contra os direitos LGBT, articulando o Plano Nacional de Cidadania LGBT e o Projeto ESH. Com a divulgação desse panfleto, o deputado conseguiu trazer o tema novamente a

9 Matéria intitulada "Jean Wyllys e Marta Suplicy relançam nesta terça-feira Frente Parlamentar Mista pela Cidadania LGBT, publicada no O Globo, em 29/03/2011. Disponível em: http://oglobo. globo.com/politica/jean-wyllys-marta-suplicy-relancam-nesta-terca-feira-frente-parlamentar-mista-pela-cidadania-lgbt-2804367 
público e novos atores começaram a aparecer em torno da discussão do Projeto ESH. O lançamento do material teve forte repercussão pública e reafirmou as principais bases argumentativas dos opositores do projeto. Em discurso na Assembleia Legislativa de Mato Grosso na mesma semana, durante audiência pública sobre o combate à pedofilia, o senador Magno Malta criticou mais uma vez o projeto ESH, ressaltando que a iniciativa era capitaneada "por uma minoria barulhenta, apoiada por parte da mídia". Seguiu afirmando que

Estão preparando um kitzinho para meninos a partir de seis anos de idade. Um filmete ensinando a beijar na boca, ensinando as crianças a se relacionar sexualmente [...] as nossas escolas se tornarão escolas preparatórias de homossexuais. Os nossos pequenos estarão na academia da homossexualidade. ${ }^{10}$

Um aspecto interessante envolve a figura do senador Magno Malta e essa afirmação, que se dá em uma audiência pública da CPI da Pedofilia, a qual o senador presidiu. O tema da violência sexual, tão caro ao campo de garantia dos direitos de crianças e adolescentes, foi capitaneado no Congresso na criação dessa CPI, que teve como seu articulador um dos principais atores contra a garantia de direitos LGBT no Congresso Nacional. Nesse contexto, a defesa dos direitos de crianças e adolescentes foi colocada em oposição aos direitos $\mathrm{LGBT}^{11}$. O desenvolvimento da polêmica em torno do projeto ESH se estruturou de forma parecida com a CPI da Pedofilia. A estratégia de seus articuladores foi mobilizar diferentes setores da sociedade em torno de uma causa ligada "à defesa das crianças", apresentadas sempre como seres frágeis e desprovidos de agência, e à defesa da "família brasileira", como se esta fosse um ente único e palpável.

No caso do projeto ESH, os "monstros" são um pretenso Estado que aceitaria a "corrupção das crianças" e um movimento LGBT que representaria os corruptores. Em diferentes momentos da polêmica, observa-se que a discussão

\footnotetext{
${ }^{10}$ Matéria intitulada "Senador critica proposta de distribuição de kit contra homofobia", publicada na Folha de São Paulo em 17/05/2011. Disponível em: http://www1.folha.uol.com.br/ cotidiano/917227-senador-critica-proposta-de-distribuicao-de-kit-contra-homofobia.shtml

${ }^{11}$ Lowenkron (2015) acompanhou em sua pesquisa os trabalhos da CPI e discutiu os atores e discursos acionados naquele processo. A autora afirma que o discurso hegemônico ao longo da CPI convocava a união de todos os "cidadãos de bem" em torno de uma "cruzada" contra um "inimigo" - ou "monstro" - que, ao "corromper a criança", ameaça a sociedade como um todo e os valores da "família" em particular.
} 
A captura das crianças e dos adolescentes: refletindo sobre controvérsias públicas envolvendo gênero e sexualidade nas políticas de educação

de temas relacionados a direitos LGBT no cenário mais público, especialmente no parlamento, apresenta-se de forma articulada. Nesse mesmo discurso, na CPI da Pedofilia, o senador Magno Malta se referiu ao projeto que criminalizaria a homofobia. O senador terminou seu discurso com uma fala de impacto em relação ao projeto de lei, afirmando que "Deus criou o macho e a fêmea. Não vai ser o Senado da República que criará o terceiro sexo"12.

Outro aspecto que chama atenção e que se mostra em diferentes momentos da polêmica é o quanto discursos focados em hierarquias relacionadas a outros marcadores sociais também se articulam. Em episódio anterior envolvendo Bolsonaro, ele havia sido denunciado como racista, em função de uma fala sua a uma entrevista na televisão. Questionado pela cantora Preta Gil sobre o que faria se um filho seu se apaixonasse por uma negra, Bolsonaro respondeu: "Preta, não vou discutir promiscuidade com quem quer que seja. Eu não corro esse risco e meus filhos foram muito bem-educados. E não viveram em ambiente como lamentavelmente é o teu"13. Após a repercussão, o deputado disse que entendeu errado a pergunta, confundindo a palavra "negra" com a palavra "gay". Em episódio de enfrentamento do deputado com a senadora Marinor Brito ${ }^{14}$, Bolsonaro reagiu acessando argumentos sexistas, ao afirmar que

Ela agrediu! Ela bateu em mim. E eu sou homofóbico? Ela é heterofóbica. Não pode ver um heterossexual na frente dela que alopra! Já que está difícil ter macho por aí, eu estou me apresentando como macho e ela aloprou. Não pode ver um heterossexual na frente. Ela deu azar duas vezes: uma que sou casado e outra que ela não me interessa. É muito ruim, não me interessa. ${ }^{15}$

${ }^{12}$ Matéria intitulada "Do senador Magno Malta: "O MEC quer criar academias de homossexualidade", publicada no site IG, em 18/05/2011. Disponível em: http://poderonline.ig.com.br/index. php/2011/05/18/do-senador-magno-malta-o-mec-quer-criar-academias-de-homossexualidade/

${ }^{13}$ Matéria intitulada "Bolsonaro volta a atacar 'kit gay' do Ministério da Educação", publicada na Folha de São Paulo, em 27/04/2011. Disponível em: http://www1.folha.uol.com.br/ poder/908104-bolsonaro-volta-a-atacar-kit-gay-do-ministerio-da-educacao.shtml

${ }^{14}$ Em debate na Comissão de Direitos Humanos da Câmara sobre o projeto que criminaliza a homofobia, vários parlamentares contrários ao projeto de lei se articularam para barrar a discussão. Após a sessão da Comissão, os deputados Jair Bolsonaro e Marinor Brito (PSOL-PA) se confrontam, pois Bolsonaro utilizou entrevistas que os defensores do projeto estavam concedendo para mostrar seu panfleto contra o Projeto ESH. A senadora tenta afastá-lo, acusando-o de homofóbico, e é acusada de tê-lo agredido.

${ }^{15}$ Matéria intitulada "Deputado Bolsonaro e senadora Marinor Brito quase saem no tapa" publicada em O Globo, em 12/05/11. Disponível em: http://oglobo.globo.com/politica/ deputado-bolsonaro-senadora-marinor-brito-quase-saem-no-tapa-2770974 
Como Brah (2006, p. 351) afirma, "estruturas de classe, racismo, gênero e sexualidade não podem ser tratadas como 'variáveis independentes' porque a opressão de cada uma está inscrita dentro da outra - é constituída pela outra e é constitutiva dela". E, nesse contexto, todas essas opressões e desigualdades de alguma forma se articulam e são retroalimentadas por uma moralidade que tem como base a reafirmação de desigualdades de gênero, raça e sexualidade e se materializa em discursos proferidos por homens que se identificam como brancos e heterossexuais ${ }^{16}$.

O que até aquele momento, pelo menos publicamente, em relação ao parlamento, era uma ação isolada de Bolsonaro, com apoio de Magno Malta e aparições esparsas de outros parlamentares tornou-se uma "bandeira" da Bancada Evangélica no Congresso. Entrou em cena o deputado Anthony Garotinho (PRRJ) como porta-voz da "força evangélica". Em discurso no plenário da Câmara, Garotinho, com o apoio de outros deputados, afirmou que "esses livros ensinam inclusive a fazer sexo anal [...] Não se vota nada enquanto não se recolher esse absurdo"17. Não podemos nos esquecer de que essas falas são a ponta mais visível de amplos setores de nossa sociedade que, mais ou menos abertamente, pactuam com os valores que estão na base desses discursos, valores esses que estão entranhados em nossa cultura há muito tempo.

No dia 25 de maio de 2011, a presidente Dilma suspendeu o Escola sem Homofobia. Com a suspensão do projeto, quando ele já havia ganhado lugar de "tema nacional", várias instituições e diferentes atores se posicionaram em relação à decisão do governo. O ESH ficou em evidência durante os meses seguintes e diferentes posicionamentos foram amplamente publicizados na mídia. Em 2012, quando Fernando Haddad, então ministro da Educação, tornou-se candidato a

${ }^{16}$ Compartilha-se, aqui, da mesma reserva enunciada pela autora sobre "as perspectivas analíticas e políticas em que a desigualdade social passa a ser personificada nos corpos dos grupos sociais dominantes - os brancos, homens ou heterossexuais em relação ao racismo, sexismo ou heterossexismo". Contudo, como ela afirma, "não podemos ignorar as relações sociais de poder que inscrevem tal diferenciação. Membros dos grupos dominantes de fato ocupam posições 'privilegiadas' dentro de práticas políticas e materiais que se ocupam dessas divisões sociais" (BRAH, 2006, p. 355).

${ }^{17}$ Matéria intitulada "Bancada evangélica diz que não vota 'nada' até esclarecer 'kit gay',, publicada na Folha de São Paulo, em 17/05/2011. Disponível em: http://www1.folha.uol.com.br/ cotidiano/917220-bancada-evangelica-diz-que-nao-vota-nada-ate-esclarecer-kit-gay.shtml 
prefeito de São Paulo, o projeto voltou à baila como instrumento de ataque ao candidato.

\section{ALGUMAS REFLEXÕES QUE O PERCURSO DO PROJETO ESCOLA SEM HOMOFOBIA PROPÕE}

O percurso do Projeto Escola sem Homofobia nos possibilita múltiplas análises e reflexões. Pretende-se, aqui, levantar alguns pontos, sem a pretensão de dar conta de toda a complexidade desse processo. Um aspecto interessante da polêmica, bastante presente nos debates em torno do projeto, é o quanto as fases da vida foram acionadas em função da posição a ser defendida. Os críticos ao projeto se remetiam, durante toda a polêmica, a uma "infância", que precisaria ser protegida de um potencial desvirtuamento financiado pelo Estado. De outro lado, os defensores do projeto responderiam a essa estratégia, acionando a ideia de "juventude", assumindo rapidamente que o projeto era voltado apenas para o ensino médio. Contudo os materiais do projeto, como uma das matérias jornalísticas "denunciou", faziam referência a estudantes do ensino fundamental (6 a 9o ano), assim como a pesquisa vinculada ao projeto foi desenvolvida em escolas do ensino fundamental da rede pública.

Trabalha-se com a hipótese de que no campo político seja mais fácil tratar de uma "juventude LGBT", em vez de uma "adolescência LGBT", pois a última expressão pode trazer implícita a politicamente perigosa ideia de "sexualização" das crianças, utilizada fortemente nos discursos daqueles que se opõem à garantia de direitos LGBT. Considera-se que é mais confortável para o conjunto de atores envolvidos com o tema da diversidade sexual e de gênero lidar em seu discurso público com um "jovem", que no senso comum está mais próximo da vida adulta do que o "adolescente", mais facilmente ligado à infância. Não importa se o "kit" foi pensado para o ensino médio ou isso foi só uma estratégia para proteger o projeto e seus proponentes, os pretensos violadores da inocência santa e mágica das crianças. O que é instigante é a utilização desse jogo: crianças/adolescentes versus jovens/quase adultos.

A presença dessa "infância" a ser protegida marca a força do acionamento da categoria "pedofilia" em todo o percurso da polêmica do projeto ESH. Praticamente todos os opositores do projeto no Congresso Nacional, que a pesquisa demonstrou serem os mesmos atores que trabalham contra o conjunto de proposições 
no Legislativo ligadas aos direitos LGBT, utilizaram a imagem da criança indefesa, "presa fácil dos pedófilos". O discurso dos oponentes do projeto reforçou uma perspectiva, bastante utilizada durante toda a polêmica, de que o pretenso enfrentamento à homofobia mascarava um "aliciamento", desvirtuamento das crianças. Essa estratégia apostava, como afirmado, na construção de uma polarização entre os defensores dos direitos das crianças e dos adolescentes e os defensores dos direitos LGBT. Essa polarização pode ser relacionada ao forte envolvimento do campo dos direitos da criança e do adolescente com o enfrentamento à violência sexual. Os defensores dos direitos da criança e do adolescente, no que tange a aspectos relacionados à sexualidade, tenderam historicamente a atuar sob uma perspectiva que reafirma um lugar passivo das crianças e dos adolescentes, um lugar de vítima (LEITE, 2013).

O tema do enfrentamento à pedofilia surgiu durante a polêmica completamente articulada a um discurso de "defesa da família". Os oponentes do ESH, ao "declararem guerra" ao projeto que desvirtuaria as crianças, faziam-no "em nome da família brasileira", como se essa família fosse um ente único e estável. Ora a "família brasileira", que os detratores do projeto defendiam, era a verdadeira família, ora ela era esse ente superior a ser sacralizado. Um aspecto fundamental na polêmica é a utilização da ideia de "defesa da família e bons costumes" em polarização com o ataque aos "homossexuais pedófilos".

O que diferenciava o Projeto Escola sem Homofobia de outras iniciativas governamentais que lidavam com as "diversidades" e não fomentaram tanta oposição? O ESH tratava claramente de adolescência e diversidade sexual e de gênero. Ao que parece, os vídeos do ESH incomodaram tanto exatamente porque apostaram em uma afirmação positiva da vivência da homossexualidade, bissexualidade, travestilidade ou transexualidade na adolescência. O material do projeto focou na existência e, poderia se dizer, resistência desses jovens na escola. O mais interessante ao olhar para a trajetória do projeto é que seus opositores focavam sua crítica na possibilidade de "ser gay" na adolescência que o projeto apresentava, daí a alcunha pejorativa "kit gay". Contudo, dado o temor dos movimentos ligados à afirmação da cidadania LGBT de lidarem com o tema da adolescência/ juventude, todo o discurso dos defensores do projeto foi de defesa da importância do enfrentamento à homofobia, e não de defesa da possibilidade de "ser gay" na adolescência/juventude. 
A captura das crianças e dos adolescentes: refletindo sobre controvérsias públicas envolvendo gênero e sexualidade nas políticas de educação

A aposta hegemônica dos defensores do projeto foi de acionamento do discurso de enfrentamento à violência - "precisamos proteger 'nossas crianças' da homofobia" -, mas foi extremamente tímida a defesa em relação à afirmação da diversidade sexual e de gênero na adolescência - "'nossas crianças e adolescentes' têm o direito a exercitarem múltiplas expressões de sexualidade e gênero". A reflexão acerca da utilização da violência como recurso para amenizar enfrentamentos entre atores e grupos que têm concepções bastante diferenciadas em relação à sexualidade é uma "chave" importante das reflexões aqui desenvolvidas, e podemos articulá-la a um processo de vitimização bastante presente no campo dos direitos humanos ${ }^{18}$.

Corrêa (2004) chama atenção ao fato de que esse debate em torno da violação está entre os desafios colocados para aqueles que pretendem contribuir com uma delimitação mais clara dos conteúdos dos direitos sexuais, pois está relacionado à tensão teórica e política entre as ênfases em objetificação e vitimização, por um lado, e prazer e erotismo e recriação, por outro. Em sua opinião, é preciso explicitar nos debates as diferenças de posição no que se refere ao "sentido" que os diferentes atores do campo dos direitos humanos atribuem à sexualidade como terreno da experiência humana. Segundo a autora, "se o campo permanecer fixado em uma ideia de sexualidade ligada ao abuso, violência e coerção, dificilmente poderemos avançar na elaboração de legislações, políticas públicas e programas de intervenção comprometidos com uma agenda positiva dos direitos sexuais como direitos humanos" (CORRÊA, 2004, p. 13).

No que se refere à articulação entre adolescência e diversidade sexual e de gênero, a vitimização pode ser utilizada como forma de "defesa", não exigindo posicionamentos explícitos de afirmação dos direitos sexuais e de livre expressão de gênero dos adolescentes. Combater a homofobia não significa reconhecer a homossexualidade como orientação sexual tão digna de respeito quanto a heterossexualidade? O que a trajetória do projeto ESH mostrou é que parece que não.

${ }^{18}$ Considera-se importante a reflexão desenvolvida por Petchesky (1999), ao afirmar que as campanhas em favor dos direitos humanos das mulheres receberam maior atenção, em geral, quando enfatizaram os piores horrores a que estas estavam submetidas. Tais campanhas capitalizaram a imagem das mulheres como vítimas. Segundo a autora, um problema é que essa construção negativa dos direitos sexuais permeia o discurso geral sobre os direitos humanos. Historicamente, a violação dos direitos humanos sempre recebeu a maior atenção (PETCHESKY, 1999, p. 26). 
Especialmente quando essa homossexualidade, bissexualidade ou transexualidade se mostra em sujeitos adolescentes. O que tem sido proposto refletir é exatamente que esse "limite de aceitação", de "viabilidade", mostra-se mais restrito quando falamos de adolescentes. E esse debate também se apresenta de forma bastante intensa no campo da educação (JUNQUEIRA, 2009). Ao que se parece, posicionar-se pela afirmação dos direitos sexuais e direitos à livre expressão de gênero dos adolescentes, e não só pelo enfrentamento à homofobia nas escolas, é um dos grandes desafios colocados para o conjunto de atores envolvidos nessa polêmica.

\section{NO RASTRO DE NOVAS CONTROVÉRSIAS}

Entre 2013 e 2014, acompanhamos os embates em torno do Plano Nacional de Educação e dos planos estaduais e municipais, em que as expressões "gênero" e "orientação sexual" foram retiradas de seus textos, em meio a batalhas quase corporais nas casas legislativas do país. E é nesse período que começamos a assistir ao acionamento da terminologia "ideologia de gênero". Vários autores têm refletido e debatido desde a gênese desse termo até o seu espraiamento por vários países e partes do mundo e diferentes formas de acionamento ${ }^{19}$ (CORRÊA, 2018; RODRIGUES; FACCHINI, 2018; AMAYA, 2017; CORNEJO-VALLE; PICHARDO, 2017; JUNQUEIRA, 2017; KUHAR; PATERNOTTE, 2017; MISKOLSCI; CAMPANA, 2017; SERRANO, 2017; VIVEROS; RONDON, 2017).

Os setores "conservadores" assumiram uma estratégia de apropriação de termos dos estudos de gênero e dos movimentos feministas, alterando seu sentido. A perspectiva de gênero, que vem dando base para toda a construção de um campo de estudos e produção de conhecimento, é vulgarizada e tratada como ideologia. Tendo como base uma perspectiva biológica reducionista do binarismo de gênero e articulada a uma hierarquização das orientações sexuais, o ideário da "ideologia de gênero" tem sido utilizado para defender a manutenção de uma ordem hierárquica e desigual entre as pessoas, em nome da defesa das crianças e dos jovens (LEITE, 2019).

\footnotetext{
19 É importante atentar-se para o fato de que essa ofensiva conservadora que verificamos no país, envolvendo especialmente questões ligadas a gênero e sexualidade, mas não só, trata-se de um fenômeno transnacional, embora se desenvolva com certas características em cada contexto nacional (BIROLI, 2018). Os temas, articulações e inclusive os discursos que dão base a essa ofensiva são bastante parecidos em diferentes partes do mundo.
} 
A captura das crianças e dos adolescentes: refletindo sobre controvérsias públicas envolvendo gênero e sexualidade nas políticas de educação

Verificamos que muitos dos argumentos utilizados na polêmica do ESH são novamente acionados nos embates em relação aos planos de educação e muitos dos atores que protagonizaram a derrubada do ESH estiveram à frente dessa nova controvérsia. Há a continuidade da argumentação sobre a existência de uma orquestração gay e feminista que defende a sexualização das crianças, o estímulo à homossexualidade e a destruição da família. A articulação de tais pânicos morais fortalece uma ideia de que o Estado estaria apoiando e financiando o "desvirtuamento" das crianças. Contudo esses discursos deixam de ter uma base mais religiosa, como foram mais claramente ancoradas as discussões no caso do ESH, e assumem uma pretensão científica. Novamente, a presença de uma "infância" a ser protegida marca a força do acionamento da categoria "pedofilia" em todo o percurso das polêmicas mais recentes. Os discursos dos oponentes do Projeto ESH e que denunciam a "ideologia de gênero" utilizam a imagem da criança indefesa, "presa fácil dos pedófilos". Reafirma-se a aposta na construção de uma polarização entre os defensores dos direitos das crianças e dos adolescentes e os defensores dos direitos LGBTI, assim como, nas polêmicas recentes, também dos direitos das mulheres.

Articulado a esses embates, deu-se o crescimento do Movimento Escola sem Partido ${ }^{20}$, que busca despolitizar o cotidiano escolar em nome de uma pretensa "neutralidade do papel da escola". Há várias proposições legislativas tramitando para aprovação em lei do programa Escola sem Partido, capitaneadas por bancadas religiosas. O Escola sem Partido, que teve seu início a partir de um discurso de enfrentamento a uma "doutrinação comunista" nas escolas, ganhou espaço na sociedade quando se ligou a setores religiosos e encampou a cruzada contra a "ideologia de gênero" (MIGUEL, 2016).

No período eleitoral para a Presidência da República, em 2018, verificamos que as expressões de sexualidade e gênero infantojuvenis tiveram muita visibilidade, no que uma matéria da Agência Pública ${ }^{21}$ chamou de "eleição do kit gay".

${ }^{20}$ Segundo Miguel (2016, p. 595), "fundado em 2004 pelo advogado Miguel Nagib, o Movimento Escola sem Partido permaneceu na obscuridade até o início da década de 2010, quando passou a ser uma voz frequente nos debates sobre educação no Brasil. Seu programa foi abraçado por todos os grupos de direita do país. É o idealizador de projetos de lei que tramitam em todo o Brasil, nas Câmaras de Vereadores e Assembleias Legislativas, e também no Congresso Nacional".

${ }^{21}$ Fundada em 2011 por repórteres mulheres, a Pública é uma agência de jornalismo investigativo sem fins lucrativos. Matéria divulgada em 17/10/2018, intitulada "A eleição do 'kit gay'”. 
Foram ressuscitados materiais quando da polêmica envolvendo o Escola sem Homofobia em 2011, e o "kit gay" transformou-se em um dos principais artefatos da campanha do presidente eleito do país, Jair Bolsonaro. O próprio Bolsonaro, deputado pouco expressivo em termos de ação legislativa e mais conhecido por sua postura pitoresca e teatral, afirmou, ainda em 2017, em entrevista ao Jornal Estado de São Paulo ${ }^{22}$, que sua carreira política foi catapultada pelo que ele cunhou como "kit gay".

Cresceu nos meios religiosos a ideia de que os adversários de Bolsonaro estariam tentando destruir a "família tradicional" e o Partido dos Trabalhadores (PT) - do qual Fernando Haddad era candidato a presidente - se valeria de livros didáticos para difundir marxismo e ideologia de gênero. O presidente eleito e seus apoiadores têm estimulado que estudantes gravem seus professores e os denunciem por "doutrinação esquerdista". Um aspecto interessante a ser refletido é que as mesmas crianças e adolescentes que seriam incapazes de reagir a um processo de "sexualização precoce", as mesmas "vítimas da ideologia de gênero", são aquelas e aqueles que estão sendo estimulados a serem agentes, protagonistas na denúncia de seus "professores doutrinadores". Se, por um lado, eles são tomados como puro objeto de violação e controle, de outro, poderiam ser sujeitos na mudança da ação educativa voltada a eles. Esse paradoxo nos traz uma reflexão sobre o estatuto de sujeito da população infantojuvenil.

O discurso dos direitos humanos foi fundamental para a afirmação do campo de garantia dos direitos de crianças e adolescentes, pois sua conformação se deu a partir do impacto de um ideário dos direitos humanos, que se fortalecia internacionalmente, no que poderíamos denominar um "campo da menoridade" no Brasil. Com a mudança do marco legal brasileiro e a aprovação do Estatuto da Criança e do Adolescente (ECA), construiu-se um novo paradigma para o direito infantojuvenil. Crianças e adolescentes deixam de ser objeto de proteção assistencial e passam a ser titulares de direitos. O Estatuto está ligado a um novo projeto de sociedade, calcado na garantia dos direitos humanos, e demanda a construção de uma nova relação do mundo adulto com a infância e adolescência, visto que a sociedade brasileira foi historicamente autoritária e tutelar com as crianças.

Disponível em: https://apublica.org/2018/10/a-eleicao-do-kit-gay/\#link1.

22 Entrevista concedida a Marcelo Godoy e publicada em 02/04/2017. Disponível em: http:// infograficos.estadao.com.br/politica/bolsonaro-um-fantasma-ronda-o-planalto/ 
A captura das crianças e dos adolescentes: refletindo sobre controvérsias públicas envolvendo gênero e sexualidade nas políticas de educação

Enfrenta-se um conjunto de mudanças e desafios, ao ter de lidar com as novas concepções que o marco legal impôs à sociedade. Os desafios impressos nessas mudanças dizem respeito fundamentalmente à necessidade de reflexão acerca dos valores e concepções construídos historicamente em nosso país em relação à infância e juventude e que se traduzem em políticas e programas de atendimento a essa categoria social. Passados quase trinta anos após a mudança do marco legal, ainda assistimos a um intenso embate de diferentes concepções em relação ao trato com o público infantojuvenil. Postulo que lidar com as crianças e os adolescentes como sujeitos de direitos é apostar na construção de uma agenda positiva em relação ao conjunto de aspectos de sua existência, inclusive o gênero e a sexualidade.

É preciso afirmar que o gênero e a sexualidade já estão na escola e ressaltar que os valores e as concepções em relação a esses temas estão em disputa cotidiana no currículo escolar. Assim, é imprescindível que comecemos a compreender a importância de pensar as expressões de gênero e sexualidade como constitutivas da vida das crianças e dos adolescentes. Todas as pessoas estão à mercê das expectativas e normas em relação ao gênero e à sexualidade desde antes do nascimento em nossa sociedade. Desde muito pequenas as crianças são massacradas por uma pedagogia do gênero e da sexualidade que vai conformando não só uma forma de viver a feminilidade e a masculinidade, uma forma "correta" de ser menino ou ser menina, como também vai conformando que ser menino ou menina do jeito certo é desejar pessoas do gênero oposto. Assim, os valores e as representações sociais hegemônicas sobre gênero e orientação sexual nos são transmitidos desde a mais tenra idade. E a escola tem ocupado um papel de reprodução e reafirmação desses valores. Aqueles que ousam confrontar essas normas, tanto de gênero quanto de sexualidade, estarão expostos às mais variadas formas de violência, das mais sutis às mais destrutivas.

Ao finalizar, podemos propor que o Projeto Escola sem Homofobia, mesmo sem ter sido executado, existiu enquanto instrumento performativo da afirmação de um adolescente/jovem gay, lésbica, bissexual, travesti e transexual. A controvérsia pública gerada a partir do ESH nos mostra a importância de se pensar as políticas públicas como processos de intervenção desenvolvidos por múltiplos agentes sociais. Para além da elaboração de uma política pública de educação voltada ao enfrentamento da homofobia, assistimos a um intricado jogo de relações, parcerias e antagonismos, no qual se forjava publicamente o caráter dessa 
política, interrogando sua premissa de respeito (ou não) aos direitos sexuais e à livre expressão de gênero de crianças e adolescentes. Em um contexto de fortalecimento de conservadorismos, é necessário reafirmar que defender os direitos das crianças e dos adolescentes é garantir a discussão de temas ligados a gênero e sexualidade na escola.

\section{REFERÊNCIAS}

ALMEIDA, Ronaldo de. A onda quebrada - evangélicos e conservadorismo. Cadernos Pagu, Campinas, SP, n. 50, 2017.

ALMEIDA, Ronaldo de e TONIOL, Rodrigo (Orgs.). Conservadorismos, fascismos e fundamentalismos: análises conjunturais. Campinas, SP: Editora da Unicamp, 2018.

AMAYA, José Fernando Serrano. La tormenta perfecta: ideología de género y articulación de públicos. Sexualidad, Salud y Sociedad, Rio de Janeiro, n. 27, p. 149-71, dez. 2017.

BIROLI, Flavia. Gênero e desigualdades: os limites da democracia no Brasil. São Paulo: Boitempo, 2018.

BRAH, Avtar. Diferença, diversidade, diferenciação. Cadernos Pagu, Campinas, SP, n. 26, p. 329-76, jan./jun. 2006.

BRASIL. Conselho Nacional de Combate à Discriminação. Brasil sem homofobia: Programa de combate à violência e à discriminação contra GLTB e de promoção da cidadania homossexual. Brasília, 2004.

CARRARA, Sérgio. Moralidades, racionalidades e políticas sexuais no Brasil contemporâneo. Mana, Rio de Janeiro, v. 21, n. 2, p. 323-45, ago. 2015.

CORNEJO-VALLE, Mónica; PICHARDO, J. Ignacio. La "ideología de género" frente a los derechos sexuales y reproductivos. El escenario español. Cadernos Pagu, Campinas, SP, n. 50, 2017.

CORRÊA, Sonia. Eleições brasileiras de 2018: a catástrofe perfeita? Sexuality Policy Watch, 12 nov. 2018. (post-scriptum fev. 2019).

CORRÊA, Sonia. Direitos sexuais numa perspectiva internacional e histórica. In: TERTO JR., Veriano et al. (Org.). Direitos sexuais e reprodutivos como direitos humanos. Porto Alegre: NUPACS, 2004. p. 7-16. 
A captura das crianças e dos adolescentes: refletindo sobre controvérsias públicas envolvendo gênero e sexualidade nas políticas de educação

CORREA, Sonia, PATERNOTTE, David e KUHAR, Roman. A globalização das campanhas anti-gênero. Sexuality Policy Watch, 25 jun 2018.

JUNQUEIRA, Rogério. "Ideologia de gênero": a gênese de uma categoria política reacionária - ou: a promoção dos direitos humanos se tornou uma "ameaça à família natural"? In: RIBEIRO, Paula R. C.; MAGALHÃES, Joanalira C. (Org.). Debates contemporâneos sobre educação para a sexualidade. Rio Grande, RS: Ed. da FURG, 2017. p. 25-52.

JUNQUEIRA, Rogério Diniz. Diversidade sexual na educação: problematizações sobre a homofobia nas escolas. Brasília: MEC/UNESCO, 2009.

KUHAR, Roman; PATERNOTTE, David (Org.). Anti-gender campaigns in Europe. Mobilizing against Equality. Brussels: Rowan \& Littlefield, 2017.

LEITE, Vanessa. "Em defesa das crianças e da família": refletindo sobre discursos acionados por atores religiosos "conservadores" em controvérsias públicas envolvendo gênero e sexualidade. Sexualidad, Salud y Sociedad - Revista LatinoAmericana, Rio de Janeiro, n. 32, p. 119-42, ago. 2019.

LEITE, Vanessa. "Impróprio para menores"? Adolescentes e diversidade sexual e de gênero nas políticas públicas brasileiras contemporâneas. 2014. Tese (Doutorado em Saúde Coletiva)- Instituto de Medicina Social, Universidade do Estado do Rio de Janeiro, 2014.

LEITE, Vanessa. Sexualidade adolescente como direito? A visão de formuladores de políticas públicas. Rio de Janeiro: EdUERJ, 2013.

LOWENKRON, Laura. O monstro contemporâneo: a construção social da pedofilia em múltiplos planos. Rio de Janeiro: EdUERJ, 2015.

MIGUEL, Luis Felipe. Da "doutrinação marxista" à "ideologia de gênero" - Escola Sem Partido e as leis da mordaça no parlamento brasileiro. Direito \& Práxis, Rio de Janeiro, v. 7, n. 15, p. 590-621, 2016.

MISKOLCI, Richard; CAMPANA, Maximiliano. "Ideologia de gênero": notas para a genealogia de um pânico moral contemporâneo. Revista Sociedade e Estado, v. 32, n. 3, p. 725-48, set./dez. 2017.

PETCHESKY, Rosalind Pollack. Direitos sexuais: um novo conceito na prática política internacional. In: BARBOSA, Regina Maria; PARKER, Richard (Org.). Sexualidades pelo avesso: direitos, identidades e poder. Rio de Janeiro: Editora 34, 1999. 
RODRIGUES, Julian; FACCHINI, Regina. "Ideologia de gênero", atores e direitos em disputa: uma análise sobre o processo de aprovação do Plano Nacional de Educação (2013-2015). In: LOPES, Alice Casimiro; OLIVEIRA, Anna Luiza A. R. Martins de; OLIVEIRA, Gustavo Gilson Sousa de (Org.). Os gêneros da escola e o (im)possível silenciamento da diferença no currículo. 1. ed. Recife: Editora UFPE, 2018.

RUBIN, Gayle. Thinking sex: notes for a radical theory of the politics of sexuality. In: NARDI, P. M.; SCHNEIDER, B. E. (Ed.). Social perspectives in lesbian and gay studies: a reader. New York: Routledge, 1998.

SERRANO, Fernando. La tormenta perfecta: Ideología de género y articulación de públicos. Sexualidad, Salud y Sociedad, Rio de Janeiro, n. 27, p. 149-71, dez. 2017.

VIVEROS, Mara; RONDÓN, Manuel Alejandro Rodríguez. Hacer y deshacer la ideología de género. Sexualidad, Salud y Sociedad, Rio de Janeiro, n. 27, p. 118-27, dez. 2017.

WEEKS, Jeffrey. Sex, politics and society: the regulation of sexuality since 1800. Londres/ New York: Longman, 1981.

\section{Sobre a autora:}

Vanessa Jorge Leite: Pós-doutorado no Instituto de Medicina Social da Universidade do Estado do Rio de Janeiro (IMS/UERJ). Doutorado e mestrado em Saúde Coletiva IMS/UERJ. Graduada em Psicologia pela Universidade Federal do Rio de Janeiro (UFRJ). Pesquisadora associada do Centro Latino-Americano em Sexualidade e Direitos Humanos (CLAM/IMS/UERJ), onde coordena o Curso de Especialização em Gênero e Sexualidade (EGeS/CLAM/UERJ). Presta consultoria a organizações da sociedade civil. Tem experiência profissional na área de defesa, promoção e garantia de direitos de crianças, adolescentes, jovens, mulheres e população LGBT. Tem dedicado seus estudos aos seguintes temas: sexualidade, gênero, direitos humanos e políticas públicas. E-mail: vanessajleite@gmail.com, Orcid: http://orcid.org/0000-0003-4384-2817

\section{Recebido em 19 de setembro de 2019 Aprovado em 2 de novembro 2019}

